\title{
MATRIZ GUT COMO DIAGNÓSTICO EM INSPEÇÃO PREDIAL: ESTUDO DE CASO EM EDÍFICIO MULTIFAMILIAR EM FORTALEZA-CE
}

\author{
ANTUNES MONTEIRO, ADRIANO \\ Profissão: Estudante \\ Instituição: ESITC \\ Estado; País: Normandia, França \\ e-mail: adrianoantunesmonteiro@gmail.com
}

\author{
MELO MONTEIRO, ADRIANE \\ Profissão: Estudante \\ Instituição: IFCE Maracanaú \\ Estado; País: Ceara, Brasil \\ e-mail: driane.mello@gmail.com
}

\author{
TEIXEIRA DA SILVA, KAROLINE \\ Profissão: Estudante \\ Instituição: ESITC \\ Estado; País: Normandia, França \\ e-mail: karolinetx@gmail.com \\ BRITO DO NASCIMENTO, DANIEL \\ Profissão: Estudante \\ Instituição: IFCE MORADA NOVA \\ Estado; País: Ceara, Brasil \\ e-mail: danieelbn@gmail.com
}

\section{RESUMO}

A inspeção predial tem o objetivo de analisar as condições técnicas, de uso e manutenção de uma edificação, muito importante para a segurança e exigida por lei em algumas cidades. A matriz de Gravidade, Urgência e Tendência (GUT) é uma ferramenta, também conhecida como Matriz de Prioridades, que auxilia na análise dos problemas e tomadas de decisões. A matriz classifica ocorrências em diferentes níveis de gravidade, urgência e tendência. Desse modo, de uma forma prática e intuitiva priorizando ações preventivas e corretivas para que dado problema seja eliminado parcial ou totalmente, auxiliando também no planejamento orçamentário. Logo, este artigo apresenta a matriz GUT como metodologia de análise no diagnóstico de inspeção predial avaliando sua eficácia no planejamento estratégico e contribuição para o relatório de inspeção, Laudo de Vistoria Técnica (LVT) e obtenção do Certificado de Inspeção Predial (CIP), na forma de estudo de caso, em edifício multifamiliar em Fortaleza/CE.

Palavras-chave: Inspeção predial, GUT, Diagnóstico, Laudo técnico.

\section{ABSTRACT}

The building inspection aims to analyze the technical conditions, use and maintenance of a building, very important for safety and required by law in some cities. The Gravity, Urgency, and Trend (GUT) matrix is a tool, also known as the Priority Matrix, that assists in problem analysis and decision making. The matrix classifies occurrences at different levels of severity, urgency, and tendency. Thus, in a practical and intuitive way prioritizing preventive and corrective actions so that a given problem is partially or totally eliminated, also assisting in budget planning. Thus, this article presents the GUT matrix as a methodology for analysis in the building inspection diagnosis, evaluating its effectiveness in strategic planning and contributing to the inspection report, Technical Inspection Report (LVT) and obtaining the Building Inspection Certificate (CIP), in case study form, in a multifamily building in Fortaleza / CE.

Keywords: Building Inspection, GUT, Diagnostic, Technical Report.

\section{INTRODUÇÃO}

É possível perceber principalmente nas grandes metrópoles e centros urbanos a enorme quantidade de prédios residenciais. Muitos deles podem apresentar problemas graves por falta de manutenção. Problemas estes que podem vir a causar acidentes e trazer prejuízos ao patrimônio e até a gerar vítimas.

No entanto, a Inspeção Predial realizada por um profissional habilitado pode evitar estes problemas, apontando as não conformidades e possibilitando o seu reparo. 
Embora ainda não seja uma obrigatoriedade nacional, muitas cidades como Fortaleza (CE), já se adiantaram e possuem sua própria legislação sobre a realização da inspeção predial. Mais do que apenas necessidade, também é lei.

Os últimos acontecimentos de colapso estrutural ocorridos na cidade de Fortaleza em 2019 tiveram grande repercussão nacional e chamou bastante atenção para esse tema e a necessidade de estar em conformidade, tanto por segurança e quanto por legalização.

Existem várias metodologias que podem auxiliar na inspeção predial e na elaboração do seu relatório. A matriz GUT é um método que tem por base o escalonamento, que identifica os problemas e os organiza em ordem de prioridade de qual deve ser primeiro resolvido. Tem uma aplicação simples e objetiva.

Esse instrumento pode ser utilizado em situações variadas como auxílio para tomada de decisão, sendo aplicada muitas vezes como instrumento complementar a outras ferramentas da Gestão da Qualidade, como a análise SWOT, Diagrama de Pareto, Brainstorming, Diagrama de Ishikawa, 5W2H etc. (COSTA et al, 2017).

Desse modo, o objetivo deste artigo é apresentar a matriz GUT como metodologia de análise no diagnóstico de inspeção predial avaliando sua eficácia no planejamento estratégico e contribuição para o relatório de inspeção, Laudo de Vistoria Técnica (LVT) e obtenção do Certificado de Inspeção Predial (CIP), na forma de estudo de caso, em edifício multifamiliar em Fortaleza/CE.

\section{MATRIZ GUT}

Criada por Charles H. Kepner e Benjamin B. Tregoe, estudiosos na resolução de questões Organizacionais e orientação de questões complexas que envolvem muitas questões (COSTA et al, 2017), a matriz GUT é um instrumento de decisão na priorização de problemas, que é comumente utilizada na análise de riscos, pois mostra as prioridades através da qualificação dos problemas. É um instrumento da qualidade complementar a outros de sistema de Gestão da Qualidade, e está ligada ao ciclo Plan, Do, Check, Act (PDCA) na etapa de planejamento, onde acontecem identificações, priorizações e definição de planos de ação (TRUCOLO et al, 2016).

Queiroz et al (2012, p. 54) corroboram dizendo que “a Matriz GUT é uma técnica utilizada para definição das prioridades dadas às diversas alternativas de ação. Essa ferramenta utiliza a listagem dos fatos e atribui pesos aos que são considerados problemas, de forma a analisá-los no contexto de sua gravidade, urgência e tendência”.

Perguntas comuns que auxiliam na decisão de utilização da técnica são: O que devemos fazer primeiro? Por onde devemos começar? Para isso, é necessário inicialmente identificar os problemas para, posteriormente, ordená-los.

O funcionamento da matriz GUT é simples, basta seguir alguns passos para montá-la, sempre levando em consideração o significado de cada uma das letras da sigla:

- Gravidade: Representa o impacto do problema analisado caso ele venha a acontecer. É analisado sobre alguns aspectos, como: tarefas, pessoas, resultados, processos, organizações etc. Analisando sempre seus efeitos a médio e longo prazo, caso o problema em questão não seja resolvido;

- Urgência: Representa o prazo, o tempo disponível ou necessário para resolver um determinado problema analisado. Quanto maior a urgência, menor será o tempo disponível para resolver esse problema. É recomendado que seja feita a seguinte pergunta: "A resolução deste problema pode esperar ou deve ser realizada imediatamente?";

- Tendência: Representa o potencial de crescimento do problema, a probabilidade do problema se tornar maior com o passar do tempo. É a avaliação da tendência de crescimento, redução ou desaparecimento do problema. Recomenda-se fazer a seguinte pergunta: "Se eu não resolver esse problema agora, ele vai piorar pouco a pouco ou vai piorar bruscamente?" (PERIAD, 2011, s.p.). 


\section{METODOLOGIA}

\subsection{Caracterização da área de estudo}

O trabalho foi realizado em um prédio multifamiliar localizado em uma região de grande valorização imobiliária na cidade de Fortaleza, Ceará, Brasil, há aproximadamente $1 \mathrm{~km}$ da orla fortalezense. O prédio tem 22 andares com seis apartamentos cada e espaços comuns como hall, salão de festas, academia, três elevadores e quadra poliesportiva, ocupando uma área total de $3.600 \mathrm{~m}^{2}$.

\subsection{Método GUT}

Para elaboração da Matriz GUT e, posteriormente, o relatório de inspeção, foram realizadas visitas periódicas acordadas com o síndico e avisadas previamente aos condôminos. Nessas visitas foram observados itens como: caixa de energia, instalação elétrica, instalação hidráulica, umidade, rachaduras, vazamentos, caixa do ar condicionado, mofo, pintura ou quaisquer outras possíveis desconformidades.

$\mathrm{Na}$ ocasião, todas as anomalias encontradas foram fotografadas e renomeadas corretamente para sua posterior identificação. As mais representativas foram anexadas ao relatório final.

Todas as observações pontuais foram anotadas em um relatório preliminar e passadas para a planilha GUT. Em seguida, após uma análise, foi adicionado suas possíveis consequências e orientações necessárias para sua correção.

Posteriormente, foram adicionados valores representativos de cada observação em relação à gravidade, a urgência e tendência. Esses valores são de interpretação pessoal. Algumas pessoas podem achar um pouco complicado devido à subjetividade, mas é adequado pensar na atribuição de valores de acordo com a explicação do Quadro 1.

Quadro 1 - Níveis de gravidade, urgência e tendência

\begin{tabular}{|l|l|l|}
\hline $\mathrm{G}=$ Gravidade & $\mathrm{U}=$ Urgência & $\mathrm{T}=$ Tendência \\
\hline $1=$ Sem Gravidade & 1 = Pode esperar & $1=$ Não irá mudar \\
\hline $2=$ Pouco Grave & 2 = Pouco urgente & 2 = Irá piorar a longo prazo \\
\hline $3=$ Grave & $\begin{array}{l}3=\text { Urgente, merece atenção a curto } \\
\text { prazo }\end{array}$ & $3=$ Irá piorar a médio prazo \\
\hline $4=$ Muito Grave & $4=$ Muito urgente & $4=$ Irá piorar a curto prazo \\
\hline $5=$ Extremamente Grave & $5=$ Necessita de atenção imediata & $5=$ Irá piorar rapidamente \\
\hline
\end{tabular}

Fonte: PALADINI, 2004, apud TRECOLO et al, 2016.

Foram utilizadas cores diferentes de acordo com cada valor apenas para facilitar na visualização, pois com uma tabela muito grande pode ficar um pouco cansativo e confuso. Foram atribuídas as seguintes cores: azul: 1; verde: 2; amarelo: 3; laranja: 4; vermelho: 5 .

Esses valores são multiplicados para estabelecer a nota final de cada anomalia. Por exemplo: se uma recebeu nota 3, 6 e 10 para gravidade, urgência e tendência, respectivamente, utiliza-se a fórmula (I) para obter a nota final 180.

$$
\text { Nota }=G \cdot U \cdot T
$$

Essas verificações ocorreram tanto nos apartamentos quanto nas áreas comuns do prédio. Todos os espaços foram verificados, devidamente localizados e analisados, para elaboração da Matriz GUT. Com ela finalizada, pôde ser feito o LVT e encaminhado para a emissão do CIP.

\section{RESULTADOS}

Para que um edifício possa receber a sua licença para habitação, é necessário ter o CIV. Para isso, o seu corpo gestor precisa contratar um profissional habilitado para a elaboração do LVT. Com o LVT em mãos, ele o encaminha ao órgão fiscalizador competente para a emissão do certificado. 
Nesse caso, a GUT é um importante método de diagnóstico e análise de prioridades que auxilia na produção do LVT. "Rodrigues (1998) argumenta que a técnica GUT é utilizada para evitar que a mistura de problemas gere confusão, isto é, quando os problemas são vários e relacionados entre si. Marshall et al., (2006) corroboram, ainda que a utilização da matriz GUT sirva para priorizar os problemas e analisar os riscos” (QUEIROZ, et al, 2012, p. 54).

Como dito anteriormente, foi feito a identificação da anomalia, bem como sua devida localização, seu registro fotográfico, sua análise e descrição das suas possíveis consequências, grau de risco e orientação para correção. Foram também atribuídos os valores referentes a gravidade, urgência e tendência de cada uma seguindo as sugestões de notas contidas no Quadro 1. Os valores são subjetivos, pois uma pessoa pode dar uma nota e outra pode dar outra. No entanto, seguir as observações e sugestões auxiliou na escolha de que valor dar para cada, como pode ser observado a seguir.

Rachadura nas cerâmicas da porta do quarto (Figura 1): essa anomalia tem grau de risco mínimo porque não é grave, pois não está relacionada a estrutura do prédio e não envolve risco a vidas, mas apenas algo pontual. Porém, traz como consequência o desconforto estético, demandando sua troca. Com tudo, ela não é urgente, pode esperar e não irá mudar. Desse modo, estabeleceu-se notas 1, 1 e 1 para a G, U e T, respectivamente.

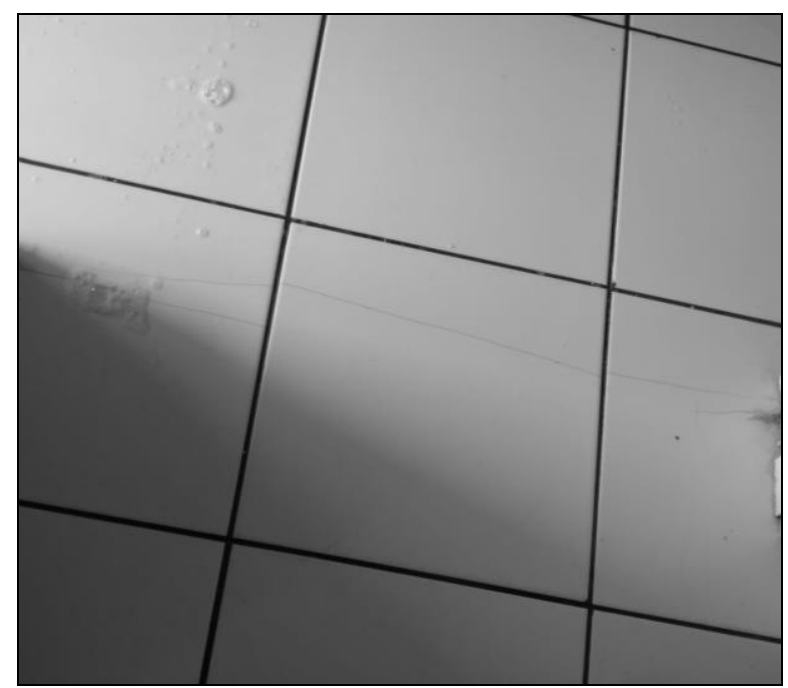

Figura 1: Rachadura nas cerâmicas (Foto_001)

Rachadura do reboco do guarda corpo da varanda do apartamento (Figura 2): recorrente em vários apartamentos do prédio estudado, essa anomalia não é grave, tem grau mínimo, pois não está relacionada a estrutura e não envolve risco de vida, mas apenas ao reboco trazendo prejuízos apenas para a estética e possivelmente uma futura infiltração no local em caso de chuva. Portanto, ela não é urgente e pode esperar. Aparentemente irá piorar a longo prazo. Desse modo, estabeleceu-se notas 1,1 e 2 para G, U e T, respectivamente.

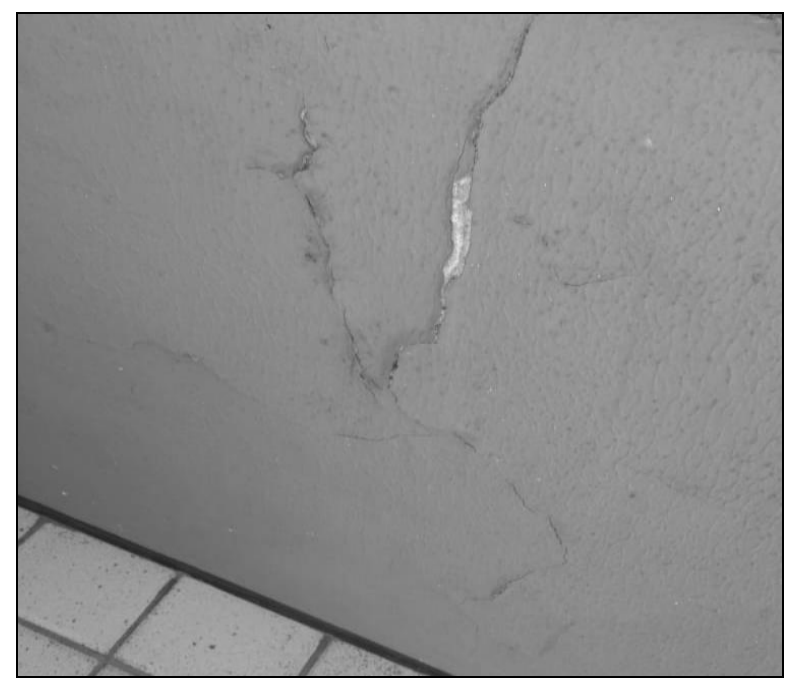

Figura 2: Rachadura no reboco do guarda corpo (Foto_002) 
Tubulações expostas que saem da laje (Figura 3): além do desconforto estético pode causar acidentes. Neste caso, o grau de risco é regular e orienta-se sua correção com correta instalação. Sua ocorrência é grave, urgente, merece atenção a curto prazo, mas que não irá mudar se não for mexido. Então, estabeleceu-se notas 3,3 e 1 para G, U e T, respectivamente.

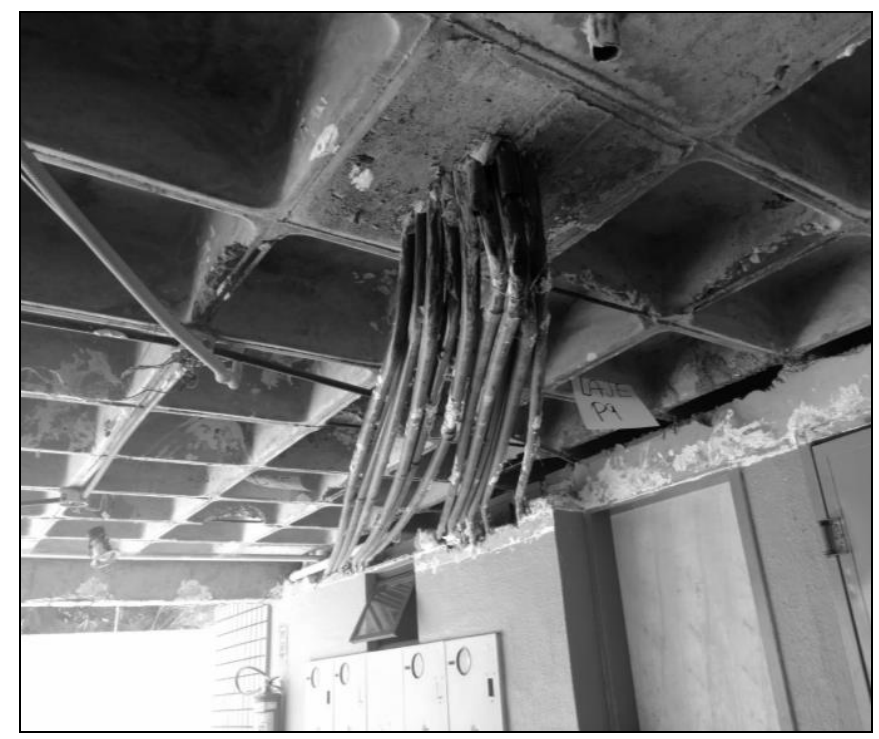

Figura 3: Tubulações expostas (Foto_003)

Desprendimento dos azulejos da parede externa do prédio (Figura 4): essa anomalia é de grau de risco crítico, pois além do desconforto estético, pode causas futuras infiltrações no local em caso de chuva e envolve risco de acidentes com na ocorrência de novos azulejos se soltarem, orientando-se a avaliação dos azulejos no geral e sua reposição. Portanto, ela é grave, muito urgente e pode piorar a curto prazo, o que deu a ela as notas 4, 4 e 4 para G, T e U, respectivamente.

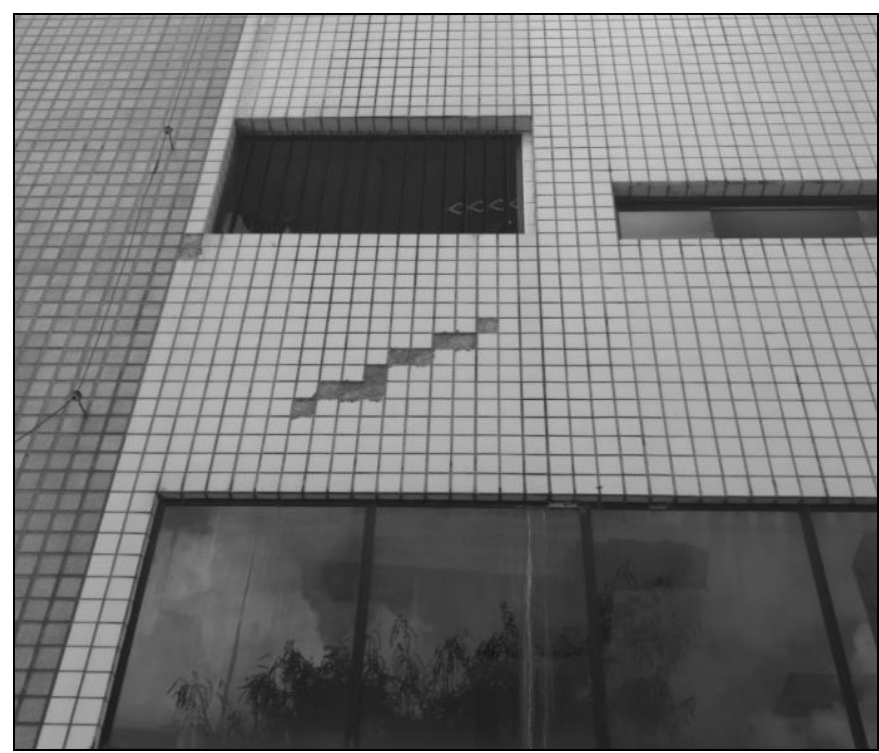

Figura 4: Desprendimento dos azulejos (Foto_004)

Rachadura de longa extensão na parede externa do prédio (Figura 5): essa rachadura causa desconforto estético e pode sugerir que haja um sério problema estrutural, o que torna a anomalia grau de risco crítico. Nesse caso, orienta-se a avaliação dos danos estruturais e sua imediata recuperação. A anomalia é extremamente grave, necessita de atenção imediata e pode piorar rapidamente. Assim, estabeleceu-se notas 5, 5 e 5 para G, T e U, respectivamente. 


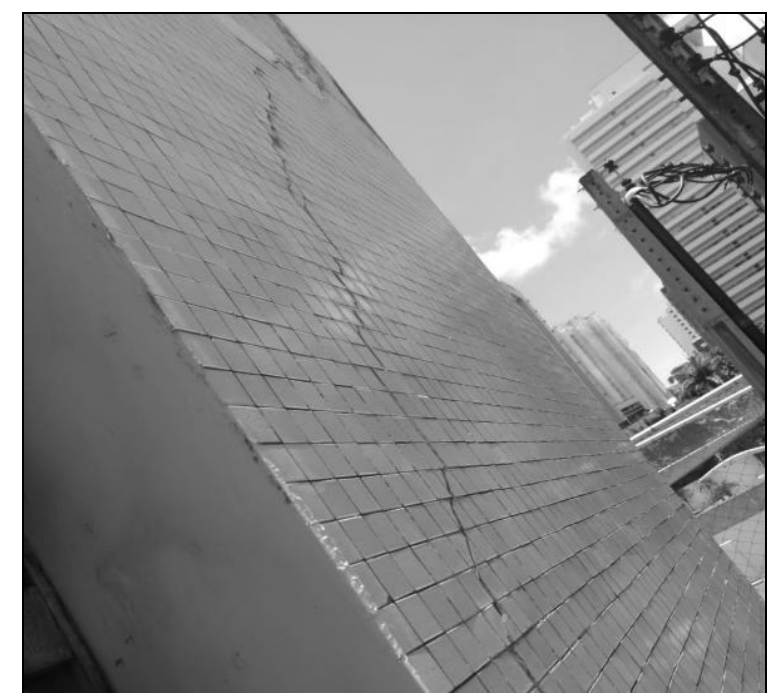

Figura 5: Rachadura de longa extensão na parede externa do prédio (Foto_005)

Assim, de acordo com as observações feitas e notas dadas, através da fórmula I foi calculada a nota final de cada anomalia e, por fim, determinado sua ordem de prioridade. A prioridade é relacionada à nota e dada de forma simples: quanto menor a nota, menor a prioridade e quanto maior a nota, maior sua prioridade de atenção.

Dado isso, foi montada a Tabela 1, que mostra a Tabela GUT feita para o trabalho de inspeção predial do edifício estudado.

Tabela 1 - GUT estudo de caso

\begin{tabular}{|c|c|c|c|c|c|c|c|c|c|c|}
\hline $\begin{array}{l}\text { Localiz } \\
\text { ação }\end{array}$ & Anomalia & Foto & Consequência & $\begin{array}{c}\text { Grau de } \\
\text { Risco }\end{array}$ & Orientação & $\mathbf{G}$ & $\mathbf{U}$ & $\mathbf{T}$ & Nota & Ordem \\
\hline $\begin{array}{l}\text { Ap. } \\
1604\end{array}$ & $\begin{array}{l}\text { Rachadura } \\
\text { nas } \\
\text { cerâmicas } \\
\text { na porta do } \\
\text { quarto }\end{array}$ & $\begin{array}{l}\text { FOTO } \\
001\end{array}$ & $\begin{array}{l}\text { Desconforto } \\
\text { estético }\end{array}$ & Mínimo & $\begin{array}{l}\text { Troca da } \\
\text { cerâmica }\end{array}$ & 1 & 1 & 1 & 1 & $5^{\circ}$ \\
\hline $\begin{array}{l}\text { Ap. } \\
0901\end{array}$ & $\begin{array}{l}\text { Rachadura } \\
\text { no reboco } \\
\text { do guarda- } \\
\text { corpo da } \\
\text { varanda }\end{array}$ & $\begin{array}{l}\text { FOTO } \\
002\end{array}$ & $\begin{array}{l}\text { Desconforto } \\
\text { estético, } \\
\text { acúmulo de } \\
\text { sujidades e } \\
\text { possível } \\
\text { infiltração }\end{array}$ & Mínimo & $\begin{array}{l}\text { Troca do } \\
\text { reboco }\end{array}$ & 1 & 2 & 2 & 4 & $4^{\circ}$ \\
\hline Laje & $\begin{array}{l}\text { Tubulações } \\
\text { expostas }\end{array}$ & $\begin{array}{l}\text { FOTO } \\
003\end{array}$ & $\begin{array}{l}\text { Desconforto } \\
\text { estético e risco } \\
\text { de acidente }\end{array}$ & Regular & $\begin{array}{l}\text { Providencia } \\
\mathrm{r} \text { instalação } \\
\text { correta }\end{array}$ & 3 & 3 & 1 & 9 & $3^{\circ}$ \\
\hline Fachada & $\begin{array}{l}\text { Desprendim } \\
\text { ento dos } \\
\text { azulejos da } \\
\text { parede } \\
\text { externa do } \\
\text { prédio }\end{array}$ & $\begin{array}{l}\text { FOTO } \\
004\end{array}$ & $\begin{array}{l}\text { Desconforto } \\
\text { estético, } \\
\text { desproteção da } \\
\text { área e risco de } \\
\text { acidentes }\end{array}$ & Crítico & $\begin{array}{l}\text { Reposição } \\
\text { dos azulejos }\end{array}$ & 4 & 4 & 4 & 64 & $2^{\circ}$ \\
\hline
\end{tabular}




\begin{tabular}{|l|l|l|l|l|l|l|l|l|}
\hline & $\begin{array}{l}\text { Rachadura } \\
\text { de longa } \\
\text { extensão na } \\
\text { Farede } \\
\text { exterior do } \\
\text { prédio }\end{array}$ & $\begin{array}{l}\text { FOTO } \\
005\end{array}$ & $\begin{array}{l}\text { Desconforto } \\
\text { estético e } \\
\text { provável } \\
\text { comprometime } \\
\text { nto estrutural }\end{array}$ & Crítico & $\begin{array}{l}\text { Avaliação } \\
\text { dos danos } \\
\text { estruturais e } \\
\text { imediata } \\
\text { recuperação }\end{array}$ & 5 \\
\hline
\end{tabular}

Fonte: Autores.

Com a Tabela 1 devidamente preenchida, chegou-se ao resultado da ordem de prioridades:

$1^{\circ}$ Rachadura de longa extensão na parede exterior do prédio.

$2^{\circ}$ Desprendimento dos azulejos da parede externa do prédio.

$3^{\circ}$ Tubulações expostas na laje.

$4^{\circ}$ Rachadura no reboco do guarda-corpo da varanda.

$5^{\circ}$ Rachadura nas cerâmicas na porta do quarto.

Logo, é possível observar que o emprego da metodologia GUT torna possível estabelecer a postura da organização que orientará suas próprias estratégias e políticas, principalmente as de médio e longo prazo. Desse modo, com essa lista de prioridades feita, a administração do edifício pode fazer o planejamento estratégico e providenciar as devidas correções dessas anomalias.

Embora a inspeção predial ainda não seja uma obrigatoriedade na legislação brasileira, muitas cidades já se adiantaram e têm suas próprias leis e normas no que compete a isso. Em todo caso, é valido lembrar que antes de ser uma obrigatoriedade legal, a inspeção é um método que visa a segurança do edifício e das pessoas, por isso é imprescindível sua realização.

\section{CONCLUSÃO}

A realização da inspeção predial é de suma importância para garantir a idoneidade e segurança tanto da edificação quanto das pessoas que ali trabalham ou residem. A sua realização por um profissional habilitado pode evitar vários problemas, desde os mais simples até os mais graves de estrutura.

No estudo de caso realizado, foi feito o levantamento das não conformidades do edifício, com seus devidos registros e observações, essenciais para o emprego da GUT, como método escolhido para auxílio na realização da emissão do relatório de inspeção.

A Matriz de Prioridade GUT é uma excelente metodologia a ser aplicada nesse setor, pois mesmo sendo de simples e prática aplicação, é bastante eficaz na identificação das não conformidades e ordenação das prioridades, possibilitando, assim, a melhor correção destas.

Com isso, é possível emitir o LVT e dar entrada no processo para a emissão do CIP. Estar com toda documentação correta em dias é essencial para evitar quaisquer problemas legislatórios e garantir a segurança do prédio e das pessoas.

\section{REFERÊNCIAS}

COSTA, et al. Aplicação da matriz GUT na gestão integrada de resíduos sólidos da cidade do Recife-PE. Revista AIDIS. Vol. 10, No. 2, 201-213. 2017. Disponível em: http://revistas.unam.mx/index.php/aidis/article/view/57757/ 54159. Acesso em: 18 dez 2019.

PERIARD, G. Matriz GUT: guia completo. Sobre administração. 2011. Disponível em: http://www.sobreadministracao. com/matriz-gut-guia-completo/. Acesso em: 18 dez 2019. 


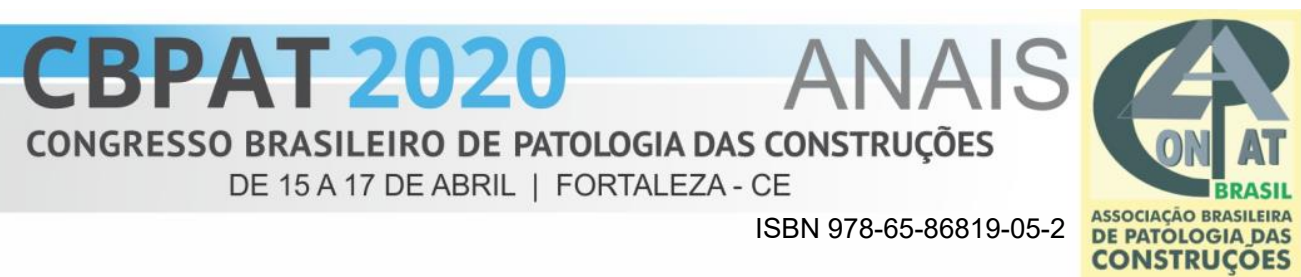

TRUCOLO, Ana. et al. Matriz GUT para priorização de problemas - estudo de caso em empresa do setor elétrico. Tecnológica Revista Cientifica. v. 5. n. 2. 2016. Disponível em: http://www.uceff.com.br/revista/index.php/revista/article/view/183. Acesso em 18 dez 2019.

QUEIROZ, J. et al. Franchising e especialização de serviços como estratégia de crescimento e manutenção: uma análise através da Matriz SWOT e GUT na DDEx - Direct to Door Express. GEPROS. Gestão da Produção, Operações e Sistemas, Ano 7, no 1, jan-mar/2012, p. 49-64. Disponível em: https://revista.feb.unesp.br/index.php/gepros/article/view/551/392. Acesso em: 18 dez 2019. 